\title{
Parameterizations for convective transport in various cloud-topped boundary layers
}

\author{
M. Sikma ${ }^{1,2}$ and H. G. Ouwersloot ${ }^{1}$ \\ ${ }^{1}$ Max Planck Institute for Chemistry, Mainz, Germany \\ ${ }^{2}$ Meteorology and Air Quality Section, Wageningen University, Wageningen, the Netherlands \\ Correspondence to: M. Sikma (martin.sikma@wur.nl)
}

Received: 3 March 2015 - Published in Atmos. Chem. Phys. Discuss.: 14 April 2015

Revised: 2 September 2015 - Accepted: 3 September 2015 - Published: 23 September 2015

\begin{abstract}
We investigate the representation of convective transport of atmospheric compounds by boundary layer clouds. We focus on three key parameterizations that, when combined, express this transport: the area fraction of transporting clouds, the upward velocity in the cloud cores and the chemical concentrations at cloud base. The first two parameterizations combined represent the kinematic mass flux by clouds.

To investigate the key parameterizations under a wide range of conditions, we use large-eddy simulation model data for 10 meteorological situations, characterized by either shallow cumulus or stratocumulus clouds. The parameterizations have not been previously tested with such large data sets. In the analysis, we show that the parameterization of the area fraction of clouds currently used in mixed-layer models is affected by boundary layer dynamics. Therefore, we (i) simplify the independent variable used for this parameterization, $Q_{1}$, by considering the variability in moisture rather than in the saturation deficit and update the parameters in the parameterization to account for this simplification. We (ii) next demonstrate that the independent variable has to be evaluated locally to capture cloud presence. Furthermore, we (iii) show that the area fraction of transporting clouds is not represented by the parameterization for the total cloud area fraction, as is currently assumed in literature. To capture cloud transport, a novel active cloud area fraction parameterization is proposed.

Subsequently, the scaling of the upward velocity in cloud cores by the Deardorff convective velocity scale and the parameterization for the concentration of atmospheric reactants at cloud base from literature are verified and improved by analysing six shallow cumulus cases. For the latter, we addi-
\end{abstract}

tionally discuss how the parameterization is affected by wind conditions. This study contributes to a more accurate estimation of convective transport, which occurs at sub-grid scales.

\section{Introduction}

Convective transport by shallow cumulus ( $\mathrm{ShCu}$ ) clouds is a key process in the lower atmosphere, as it regulates the partitioning of surface fluxes (Vilà-Guerau de Arellano et al., 2014; Lohou and Patton, 2014) and the temporal evolution of chemical reactants (Vilà-Guerau de Arellano et al., 2005; Ouwersloot et al., 2013). By venting air from the atmospheric boundary layer (ABL) to the free troposphere, $\mathrm{ShCu}$ strongly influence the ABL evolution, temperature, moisture content, and the variability of chemical species (Sorooshian et al., 2007; van Stratum et al., 2014). Besides their local effects, $\mathrm{ShCu}$ contribute strongly to the spread in the estimation of climate sensitivities by affecting both longwave (greenhouse warming) and shortwave (reflective cooling) radiation (Boucher et al., 2013). This makes it essential to represent $\mathrm{ShCu}$ and their effects accurately in atmospheric chemistry, climate and weather prediction models. However, due to the relatively coarse resolution of these models $(\sim 10-200 \mathrm{~km}$ globally), $\mathrm{ShCu}(\sim 0.5-1 \mathrm{~km})$ need to be treated as a sub-grid phenomena and are therefore required to be parameterized.

The impact of convective transport on atmospheric state variables (e.g., moisture and temperature) can be parameterized in large-scale models by using a convective adjustment scheme (e.g. Betts, 1986), an eddy-diffusion scheme (e.g. Soares et al., 2004) or the mass flux approach (e.g. Bechtold et al., 2001; Bretherton et al., 2003). In this study, we 
mainly focus on the latter, which also allows for convective transport of chemical compounds. The mass flux approach is based on the mass continuity equation, where the mass flux is defined as the difference between the lateral entrainment and detrainment rate. By analysing 10 numerical experiments performed by large-eddy simulations (LES), we investigate three key parameterizations that can be used to represent mass transport in large-scale models, namely, the area fraction of clouds, the upward velocity in the cloud cores and the concentrations at the cloud base. The latter is also applicable when a convective adjustment or eddy-diffusion scheme is employed.

As the initiation of $\mathrm{ShCu}$ formation depends on the surface forcing and the thermodynamic state of the ABL, we discriminate between two situations: (i) the marine $\mathrm{ABL}$, and (ii) the continental ABL. Since the formation of $\mathrm{ShCu}$ in the marine $\mathrm{ABL}$ is characterized by a nearly constant surface forcing, resulting in steady-state conditions, this situation has been extensively studied (e.g., Neggers et al., 2004; de Rooy and Siebesma, 2008; Suselj et al., 2013). The marine steady-state $\mathrm{ShCu}$ case used in this study is the Barbados Oceanographic and Meteorological Experiment (BOMEX; Holland and Rasmusson, 1973). On the other hand, the continental ABL is affected by a diurnal cycle in the surface forcing. The large variation in surface forcing during the day drive the initiation of $\mathrm{ShCu}$ formation, therefore impacting the dynamical structures in the ABL (Horn et al., 2015). As this situation is harder to study and therefore less investigated, four continental campaigns are selected, ranging from the mid-latitudes to the tropics, to serve as inspiration for the LES numerical experiments: the Tropical Forest and Fire Emissions Experiment (TROFFEE; Karl et al., 2007), the Gulf of Mexico Atmospheric Composition and Climate Study (GoMACCS; Jiang et al., 2008), the Small Cumulus Microphysics Study (SCMS; Neggers et al., 2003) and the Atmospheric Radiation Measurements (ARM; Brown et al., 2002).

In this work, we simplify the statistical cloud area fraction parameterization as described by Cuijpers and Bechtold (1995, hereafter CB95) by considering the variability in moisture rather than the saturation deficit. By not applying the simplifications present in previous literature (e.g. Neggers et al., 2006), we develop a general formulation that shows an unambiguous dependency of the cloud area fraction on the independent variable, $Q_{1}$, for a wide range of thermodynamic conditions. For this, we perform 10 distinct numerical simulations, where we first focus on deriving a consistent representation for the total $\mathrm{ShCu}$ cover. Furthermore, the assumption made by Neggers et al. (2006, hereafter NG06), that the cloud area fraction parameterization can be used for the representation of the area fraction of active clouds, was recently shown not to be valid for a tropical (TROFFEE) case (Sikma et al., 2014). Here, we build on this finding by proposing a novel parameterization for the area fraction of active clouds, which is appropriate for convective transport. Subsequently, extending the work of Ouwersloot et al.
(2013) and van Stratum et al. (2014), we present improvements on the scaling of the convective velocity. As a result, we are able to accurately describe the mass flux in $\mathrm{ShCu}$. Lastly, we show that the parameterization for concentrations of chemical species at cloud base, as described by Ouwersloot et al. (2013), can be used under a wide range of conditions, although dynamical segregation slightly influences the results. As shown by Ouwersloot et al. (2011), the chemical variability in clear sky conditions is affected by ABL dynamics, creating regions of high and low concentrations, thereby modifying the mean reactivity. Since $\mathrm{ShCu}$ impact the dynamical structures in the ABL (Horn et al., 2015), it will enhance this segregation of species (Kim et al., 2004). As below the $\mathrm{ShCu}$, the concentrations of chemical species differ more from cloud-layer concentrations than the mean concentrations in the ABL (Ouwersloot et al., 2013). Our findings can be used in large-scale models to represent sub-grid scale convective transport, or in conceptual models to investigate $\mathrm{ShCu}$ interactions (e.g., Vilà-Guerau de Arellano et al., 2012; van Stratum et al., 2014). Furthermore, as the vertical velocity and cloud cover are essential to calculate cloud microphysics and radiation feedbacks properly (Arakawa, 2004), our results enhance their representation in global models.

The next section introduces the theory of mass flux and is followed by descriptions of the model and numerical experiments. In the results, we first explore the effects of cloud venting on the temporal evolution of $\mathrm{ShCu}$. This is followed by parameterizations of the area fraction of $\mathrm{ShCu}$ venting and a scaling of the vertical velocity within cloud cores. Combined, these two parameterizations yield the kinematic mass flux, whose representation we investigate. We finalize with a validation and adjustment of the parameterization for the concentrations of chemical species at cloud base. While doing so, we discuss the role of dynamical segregation in the ABL.

\section{Methodology}

\subsection{Cloud types and cloud distinction}

Following Stull (1985), we discriminate between different cloud types for convective transport predictions, as not all clouds transport ABL air towards the free troposphere. Forced clouds, related to air parcels that reach the lifting condensation level, are buoyantly too weak to reach the level of free convection. Consequently, forced clouds are neglected in this study. Clouds that reach the level of free convection are marked as active clouds, as the latent heat release increases the in-cloud buoyancy, thereby enhancing cloud growth. As a result, they affect the underlying atmosphere by venting. When the active clouds decouple from the ABL thermals, they lose their supply of energy and become passive. As a result, they do not contribute to the mass transfer anymore (Stull, 1985; Siebesma et al., 2003). 
The part of the domain in which convective transport occurs is quantified by the area fraction of clouds, which is defined at each level independently (Siebesma et al., 2003; Ouwersloot et al., 2013). Note that we cannot use cloud cover, as this property is not locally determined but based on the vertically integrated liquid water path. Furthermore, we distinguish in the remainder of the paper between all clouds and cloud cores, i.e. active clouds, with subscripts ${ }_{c}$ and ${ }_{c c}$, respectively. As a result, we can distinguish four indicators for cloud presence, namely, cloud cover $\left(c_{\mathrm{c}}\right)$, cloud core cover $\left(c_{\mathrm{cc}}\right)$, area fraction of clouds $\left(a_{\mathrm{c}}\right)$ and area fraction of cloud cores $\left(a_{\mathrm{cc}}\right)$.

\subsection{Mass flux parameterization}

Mass transport can be approximated as the kinematic mass flux $(M)$ multiplied with the spatial difference in the concentrations of chemical species at cloud base $(\phi)$ (Betts, 1973):

$\overline{w^{\prime} \phi^{\prime}}=M\left(\phi_{\mathrm{cc}}-\bar{\phi}\left(z_{\mathrm{b}}\right)\right)$,

where $\phi_{\mathrm{cc}}$ indicates the value in the cloud core, and $\bar{\phi}\left(z_{\mathrm{b}}\right)$ indicates the domain-averaged value at cloud base.

The kinematic mass flux, $M$, is defined by the area fraction of cloud cores $\left(a_{\mathrm{cc}}\right)$, the difference between the cloud core vertical velocity $\left(w_{\mathrm{cc}}\right)$ and the domain-averaged vertical velocity at cloud base $\left(\bar{w}\left(z_{\mathrm{b}}\right)\right)$ (Betts, 1973), through

$M=a_{\mathrm{cc}}\left(w_{\mathrm{cc}}-\bar{w}\left(z_{\mathrm{b}}\right)\right)$

In the remainder of this paper, we assume $\bar{w}\left(z_{\mathrm{b}}\right)$ to be zero. For models that run on a coarser grid resolution than the width of a cloud core, the variables of Eq. (2) cannot be resolved explicitly and therefore need to be parameterized. We start by parameterizing the area fraction of cloud cores $\left(a_{\mathrm{cc}}\right)$. NG06 approximated $a_{\mathrm{cc}}$ by the total area fraction of clouds $\left(a_{\mathrm{c}}\right)$. The parameterization of $a_{\mathrm{c}}$ is developed by CB95, which uses local variables that depend on temperature and moisture, and is expressed by

$a_{\mathrm{c}}=0.5+\beta \arctan \left(\gamma \cdot Q_{1}\right)$

where the constants $\beta=0.36$ and $\gamma=1.55$ represent a fit through the LES results of CB95. $Q_{1}$ is calculated as

$Q_{1}=\frac{\bar{s}}{\sigma_{\mathrm{s}}}$

Here, $s$ denotes the saturation deficit in $\mathrm{kg} \mathrm{kg}^{-1}$ and $\sigma_{\mathrm{s}}$ indicates the standard deviation of $s$. Lenderink and Siebesma (2000) assumed for simplicity that $Q_{1}$ can be represented as

$Q_{2}=\frac{q_{\mathrm{t}}-q_{\mathrm{s}}}{\sigma_{q}}$,

where $q_{\mathrm{t}}$ and $q_{\mathrm{s}}$ are, respectively, the total and saturation specific humidity, and $\sigma_{q}$ is the spatial standard deviation of the specific humidity. Based on this work, NG06 applied this expression for $a_{\mathrm{cc}}$, while the $Q_{2}$ is replaced by $Q_{3}$, which is further simplified to be applicable in a mixed-layer slab model, according to

$Q_{3}=\frac{\left\langle q_{\mathrm{t}}\right\rangle-\left.q_{\mathrm{s}}\right|_{\mathrm{h}}}{\left.\sigma_{q}\right|_{\mathrm{h}}}$.

Here, $\left\langle q_{\mathrm{t}}\right\rangle$ is the total specific humidity averaged over the mixed layer (indicated by angle brackets) and $\left.q_{\mathrm{s}}\right|_{\mathrm{h}}$ and $\left.\sigma_{q}\right|_{\mathrm{h}}$ represents the respective values at the mixed-layer top. Although these adapted variables indeed coincidentally converted the expression for $a_{\mathrm{c}}$ to a reasonable prediction for $a_{\mathrm{cc}}$ for the case evaluated by NG06, we demonstrate in Sect. 3.2 that this is not valid for all thermodynamic and dynamic conditions and that a different formulation should be applied.

As shown by Neggers et al. (2004), the cloud core vertical velocity can be scaled with the Deardorff convective velocity scale $\left(w_{*}\right)$ (Deardorff, 1970). Building on this work, Ouwersloot et al. (2013) and van Stratum et al. (2014) showed for several $\mathrm{ShCu}$ cases that the inclusion of a prefactor improved this scaling:

$w_{\mathrm{cc}} \approx 0.84 w_{*}$,

which will be further extended in this study. Furthermore, as shown by Ouwersloot et al. (2013), the concentration of chemical species at the base of the active clouds can be parameterized as:

$\phi_{\mathrm{cc}}-\bar{\phi}\left(z_{\mathrm{b}}\right) \approx-1.23\left(\bar{\phi}\left(z_{\mathrm{b}}\right)-\langle\phi\rangle\right)$.

\subsection{LES model}

The numerical model used in this study is DALES 4.0. This version contains several improvements over version 3.2 (Heus et al., 2010), including additional elements (e.g. new landsurface submodels Vilà-Guerau de Arellano et al., 2014) and the introduction of an anelastic approximation for density changes with height (Boing et al., 2014). In DALES, most $(\sim 90 \%)$ of the turbulent processes are solved explicitly in a convective $\mathrm{ABL}$ when run on a grid resolution of $100 \mathrm{~m}$ or less. As a result, only parameterizations for the smaller scale turbulent structures are needed, which makes it an adequate tool to use in our study. With the use of the Boussinesq approximation, the filtered Navier-Stokes equation is solved (Heus et al., 2010). Furthermore, DALES consists of no-slip boundary conditions at the bottom and periodic boundary conditions at the sides. At the top of the domain, a sponge layer is present which damps fluctuations caused by, e.g., convection waves.

\subsection{Numerical experiments}

In all cases, the horizontal grid resolution is set to $50 \mathrm{~m} \times$ $50 \mathrm{~m}$, which covers an area of $12 \mathrm{~km} \times 12 \mathrm{~km}$. A larger domain or increase in grid resolution proved not to be of significance. The vertical resolution and extent are case-dependent 
Table 1. Experimental setup of the shallow cumulus and stratocumulus cases.

\begin{tabular}{lrrrll}
\hline Case & $\begin{array}{r}\text { Vertical } \\
\text { resolution } \\
{[\mathrm{m}]}\end{array}$ & $\begin{array}{r}\text { Vertical } \\
\text { extent } \\
{[\mathrm{m}]}\end{array}$ & $\begin{array}{r}\text { Wind } \\
u \text { comp. } \\
{\left[\mathrm{m} \mathrm{s}^{-1}\right]}\end{array}$ & Case type & $\begin{array}{l}\text { Reference to LES case/ } \\
\text { Comments }\end{array}$ \\
\hline TROFFEE & 20 & 5990 & 0.0 & Continental ShCu & Ouwersloot et al. (2013) \\
TROFFEE+ & 20 & 5990 & 5.0 & Continental ShCu & Adapted, including wind \\
GoMACCS & 25 & 4988 & 0.0 & Continental ShCu & Jiang et al. (2008) \\
SCMS & 20 & 3990 & $5.65685^{\mathrm{a}}$ & Continental ShCu & Neggers et al. (2003) \\
SCMS - & 20 & 3990 & 0.0 & Continental ShCu & Adapted, removing wind \\
ARM & 20 & 4490 & 10.0 & Continental ShCu & Brown et al. (2002) \\
BOMEX & 40 & 3180 & $-8.75^{\mathrm{b}}$ & Marine ShCu & Siebesma et al. (2003) \\
SCMS & 20 & 3990 & $5.65685^{\mathrm{a}}$ & Transition case & Adapted, decrease of $2 \mathrm{~K}$ in $\theta$ \\
ATEX & 20 & 3990 & $-8.0^{\mathrm{b}}$ & Transition case & Stevens et al. (2001) \\
DYCOMS-II & 10 & 1595 & $3.02^{\mathrm{b}}$ & Marine stratocumulus & Stevens et al. (2005) \\
\hline a Rotated wind vector which is comparable with the actual SCMS case. & \\
b Height-dependent wind profiles, starting at surface. A more detailed description can be found in the references.
\end{tabular}

and are listed in Table 1. The direction of the wind is set in the $x$ direction ( $u$ component), but differences are present in the velocities (Table 1). Also the case-dependent surface kinematic heat and moisture fluxes are prescribed. Furthermore, the ABL top is defined as the height where the gradient of the virtual potential temperature $\left(\theta_{\mathrm{v}}\right)$ exceeds $50 \%$ of the maximum gradient in the vertical profile of $\theta_{\mathrm{v}}$ (Ouwersloot et al., 2011).

Ten numerical experiments are run to simulate a range of $\mathrm{ShCu}$ and stratocumulus cases. Regarding the $\mathrm{ShCu}, 5$ situations (TROFFEE, GoMACCS, SCMS, ARM, BOMEX) are selected. Additionally, TROFFEE + and SCMS - consider an adapted wind velocity compared to the original TROFFEE and SCMS cases, respectively. The SCMS resents an adaptation on SCMS, where the initial vertical profile of $\theta$ is lowered by $2 \mathrm{~K}$. This is done to represent a transition from stratocumulus to shallow cumulus, as discussed in Sect. 3.2. Regarding the stratocumulus, 2 situations (ATEX and DYCOMS-II) are analysed.

The $\mathrm{ShCu}$ simulations start in the early morning and are based on daytime convective conditions. The radiation is calculated as a function of time, depending on the geophysical location. The chemical mechanism applied in the $\mathrm{ShCu}$ cases is identical to that described in Ouwersloot et al. (2013) and contains 20 reactant species and three passive tracers. The latter are an emitted tracer (INERT; emission of $1 \mathrm{ppb} \mathrm{m} \mathrm{s}^{-1}$ ), an inert species that is initially only present in the ABL (BLS) and an inert species that is initially present in the free troposphere (FTS). To ensure that the reactions are fully resolved, the time step is forced to a maximum of $1 \mathrm{~s}$. For all cases, the data are stored at a 1-min interval.

The stratocumulus experiments are solely performed to include representative data for the upper regime of the total cloud area fraction parameterization. Therefore, no chemical scheme is applied.

\section{Results and discussion}

\subsection{Temporal evolution of shallow cumulus}

The temporal evolution of the total and active cloud area fraction is presented in Fig. 1. The cases TROFFEE and ARM are clearly affected by a different partitioning in sensible and latent heat fluxes, caused by the diurnal cycle in incoming solar radiation. This demonstrates that the initiation of $\mathrm{ShCu}$ formation is dependent on the surface forcing. As a result, the $\mathrm{ShCu}$ start to develop from mid-morning and diminish in the late afternoon. The GoMACCS and SCMS cases show different dynamics compared to TROFFEE or ARM, as $\mathrm{ShCu}$ start to develop in the early morning (06:30 and 07:00 LT, respectively). This can be explained by a high relative humidity in the initial profiles at the start of the day, therefore favouring cloud formation (not shown). The reason for these high values can be found in the geophysical location of these cases, which are close to the ocean, even though they are classified as continental cases. In contrast to the continental numerical experiments, the BOMEX case is characterized by a nearly constant surface forcing over the ocean and is therefore classified as a marine steady-state case. In the first half an hour, moisture and heat is building up in the ABL, which causes the sudden formation of $\mathrm{ShCu}$ around 05:30 LT. After 08:00 LT, the transport of energy is proportional to the supply of energy from the surface fluxes, so the temporal evolution of the area fraction of clouds and cores is in steady-state.

As is visible in Fig. 1, all continental $\mathrm{ShCu}$ cases show a time lag of 1 hour in the initiation of $a_{\mathrm{cc}}$ compared to $a_{\mathrm{c}}$. This can be explained by forced clouds, which are dominant during the first hour. This is also visible in Fig. 2a, where the ratio between $a_{\mathrm{c}}$ and $a_{\mathrm{cc}}$ is shown. By focusing on the forced phase, it is visible that the area fraction of clouds increases with time, but that almost no active clouds are present. It is interesting to note that the dynamics in the BOMEX case are 

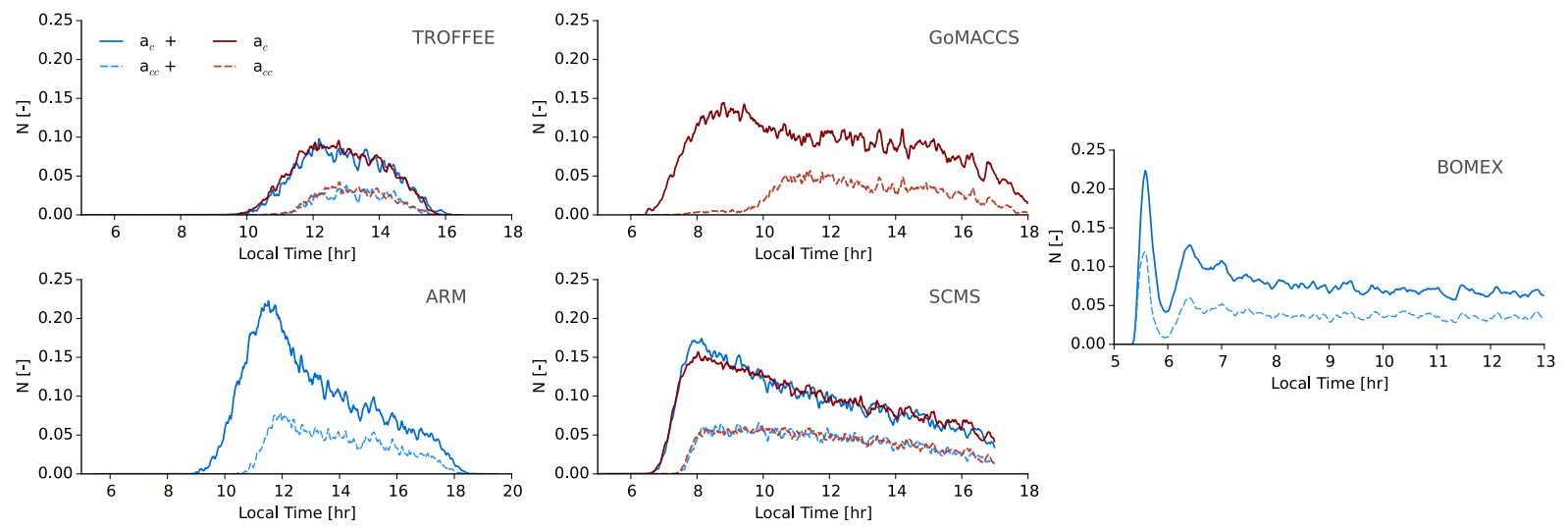

Figure 1. Temporal evolution of the domain-averaged maximum area fraction $(N)$ of clouds and cores for the ShCu cases (Table 1). The blue lines denote an experiment with wind (indicated with a "+"), while the red lines indicate a free convection case.
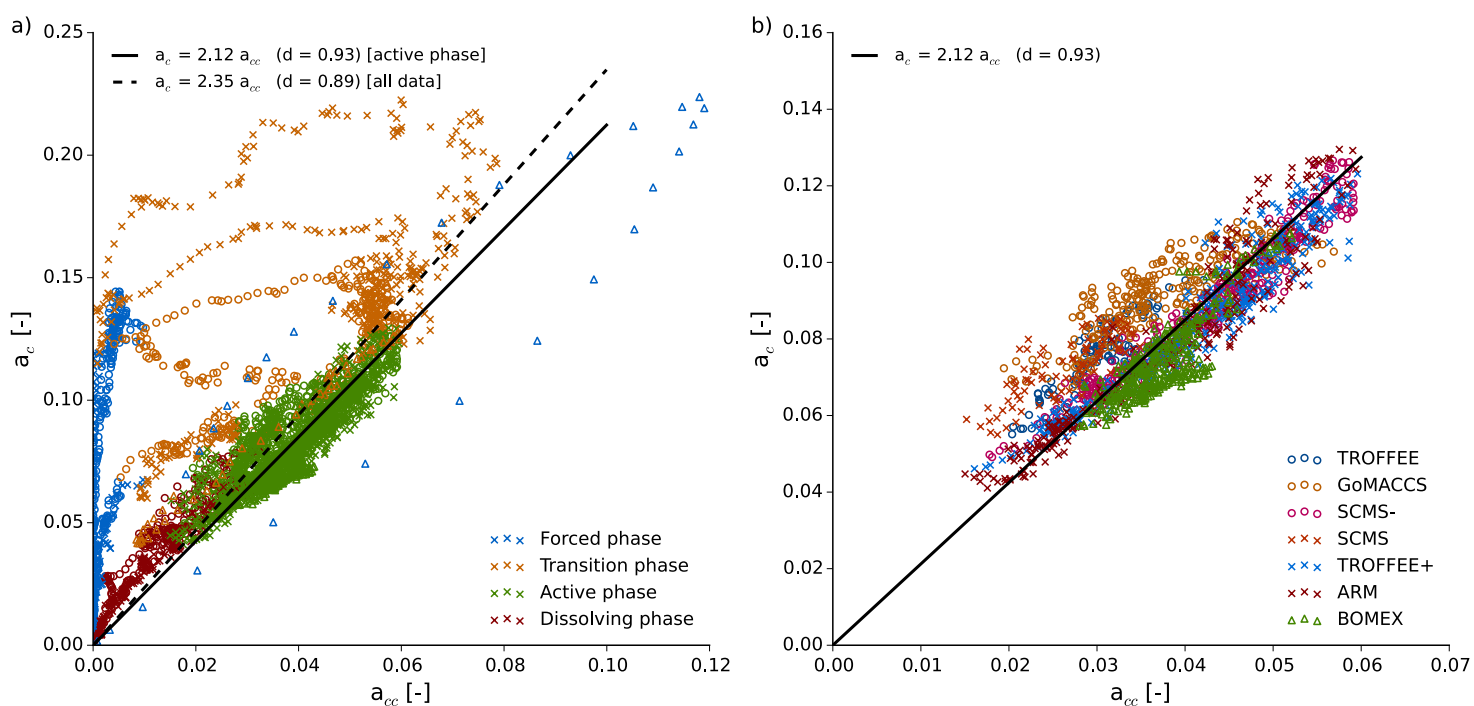

Figure 2. Scaling of the area fraction of clouds as a function of the area fraction of cloud cores. In panel (a) all data are presented, where a distinction is made between different phases of convection during the day. The lines represent the best fit through the active phase and all data, forced through 0 . In panel (b) the selected data are shown for each $\mathrm{ShCu}$ case. Circles indicate free convection situations, while crosses indicate wind situations. To differentiate BOMEX from the other cases, BOMEX is marked with triangles in panels (a) and (b). Furthermore, $d$ represents the index of agreement.

not comparable with the other cases, since it does not start in this forced phase, as mentioned earlier. In the next phase, the transition phase, the area fraction of clouds remains roughly equal, but the forced clouds are replaced by active clouds. During this process, the $a_{\mathrm{cc}}$ increases fast, indicating that the threshold for active $\mathrm{ShCu}$ growth is overcome. At the end of the transition phase, cloud venting affects the sub-cloud layer structures by redistributing thermals (Horn et al., 2015). As this transport of energy out of the sub-cloud layer affects the thermal structures, the area fraction of forced clouds decreases due to a decrease in the amount of thermals that reach the cloud layer. The area fraction of active clouds is not significantly affected by this process, while $a_{\mathrm{c}}$ decreases, so that the $\frac{a_{\mathrm{cc}}}{a_{\mathrm{c}}}$ ration increases. This process is clearly visible in the ARM and GoMACCS case (Fig. 1). When the transport of energy is proportional to the increase in energy by the surface fluxes, we identify this period as the active phase. During the active phase, the ratio between $a_{\mathrm{c}}$ and $a_{\mathrm{cc}}$ is roughly constant $\left(a_{\mathrm{c}}=2.12 a_{\mathrm{cc}}\right)$, while both gradually decrease in time. In the final phase, the dissolving phase, the number of active clouds reduces rapidly due to the diminished surface forcing. In other words, the clouds decouple from the boundary layer thermals and are transformed into passive clouds. As such, the ratio between passive and active clouds increases (see Fig. 2a). 

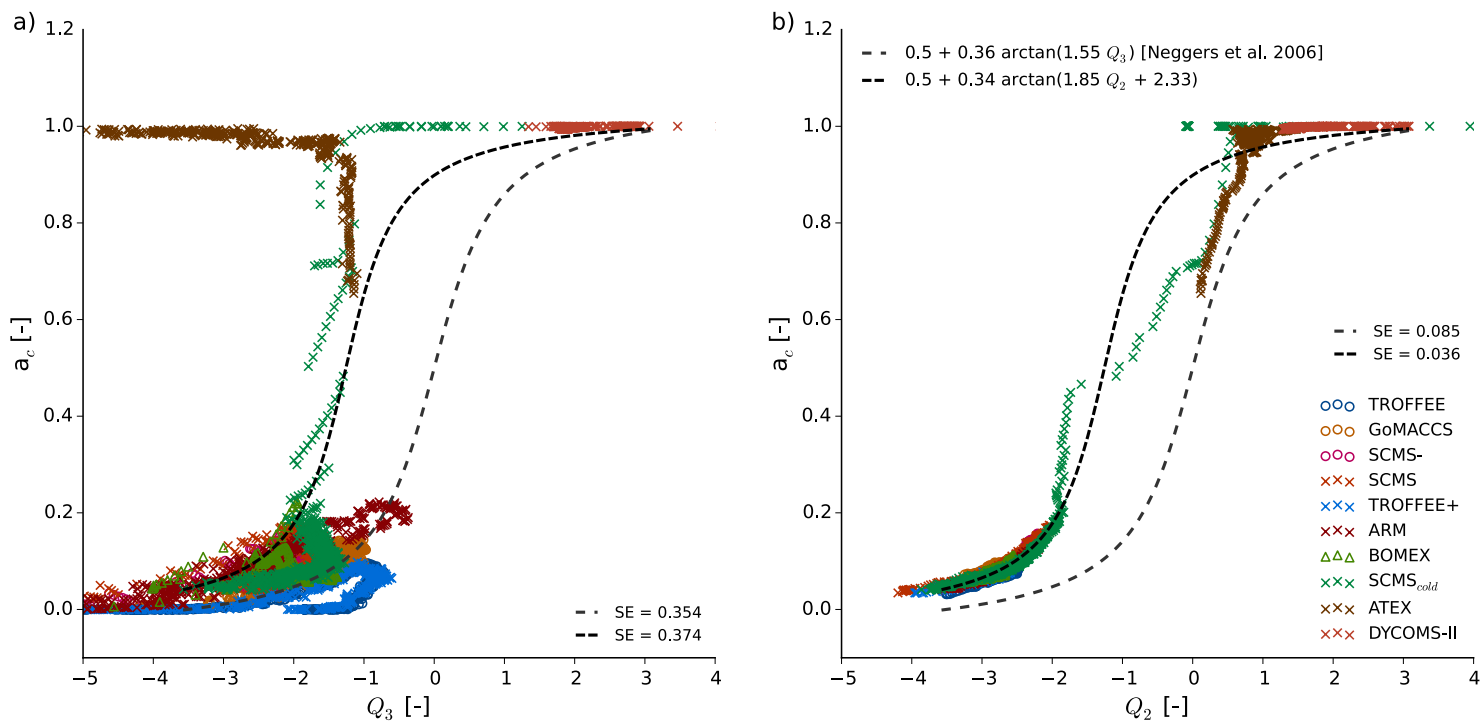

Figure 3. Area fraction of clouds as (a) a function of the normalized saturation deficit $\left(Q_{3}\right.$; Eq. 6) as described in Neggers et al. (2006) and (b) as a function of the normalized saturation deficit at cloud base $\left(Q_{2}\right.$; Eq. 5). Negative $Q_{2}$ and $Q_{3}$ values indicate ShCu clouds, while positive values denote stratocumulus clouds. The dashed lines indicate the parameterizations based on $Q_{3}$ and $Q_{2}$. SE represents the residual standard error.

To only consider the clouds that enable vertical exchange, we perform a selection procedure based on the time period when the presence of $a_{\mathrm{cc}}$ is high. We show in Fig. $2 \mathrm{~b}$, that during this time period, $a_{\mathrm{c}}$ and $a_{\mathrm{cc}}$ are coupled, but $a_{\mathrm{c}}$ decreases faster by a factor of $2.12(d=0.93)$. Here, $d$ represents the index of agreement (Wilmott, 1981). This rough relationship is a valid first approximation, but one should note that the exact factor differs between conditions and that an independent parameterization of both components is needed, which will be derived in Sect. 3.2. To show the importance of this selection procedure, we compare our (selected) data with the data (no selection) from van Stratum et al. (2014). Their relationship of $2.46(d=0.77)$ is higher than ours, indicating that the effects of mass transport are underestimated, which decreases the accuracy of the mass transport parameterizations. Therefore, in the remainder of this paper, we use the selected data to evaluate the parameterizations and scaling for $\mathrm{ShCu}$ transport.

\subsection{Parameterizing the area fraction}

To asses the validity of the simplified statistical cloud area fraction parameterization (hereafter $a_{\mathrm{c}}$-parameterization) of NG06 (Eq. 12 therein) under different thermodynamic conditions, ten numerical experiments are performed to simulate a wide range of $\mathrm{ShCu}$ and stratocumulus cases (see Sect. 2.4). As shown in Fig. 3a, the $a_{\mathrm{c}}$-parameterization of NG06 is not able to consistently represent the total cloud area fraction. Furthermore, by using $Q_{3}$, no clear dependency is visible of the cloud area fraction on specific moisture conditions. An explanation for this could be found in the dependency of
$Q_{3}$ (Eq. 6) to the volume of the ABL and the thickness of the transition zone, i.e. the region between cloud base and ABL. This dependency is only introduced in NG06, since $Q_{1}$ in CB95 and $Q_{2}$ are evaluated locally. Although NG06 simplified the expression for $a_{\mathrm{c}}$ with the help of Lenderink and Siebesma (2000) to reproduce the occurrence of active clouds with an atmospheric mixed-layer model, we show that this simplification can introduce significant errors depending on the evaluated case. Therefore, a revision of the $a_{\mathrm{c}^{-}}$ parameterization is needed such that the cloud area fraction can be reproduced for a wide range of atmospheric conditions. Furthermore, an independent representation of the active cloud area fraction, necessary for convective transport, is needed. In these analyses, we use the locally determined $Q_{2}$ (Eq. 5) as an indicator.

To include a wide range of boundary layer physics and cloud conditions between the $\mathrm{ShCu}$ and stratocumulus cases (i.e., between $Q_{2}=-2$ and 1), two additional transition sim-

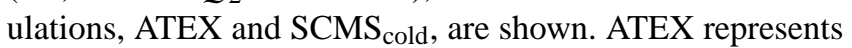
a case where $\mathrm{ShCu}$ convection starts to develop, but an inversion causes the build up of moisture near the ABL top, resulting in a stratocumulus layer. Another approach is used for the $\mathrm{SCMS}_{\text {cold }}$ simulation, where the initial vertical profiles of $\theta$ were decreased by $2 \mathrm{~K}$. As a result, the relative humidity is close to $100 \%$ near ABL top in the morning, thereby creating a stratocumulus layer. When the surface fluxes start to increase, convection starts to occur and the stratocumulus layer breaks. As is visible in Fig. 3b, a typical $\mathrm{ShCu}$ situation is present in the late afternoon which is comparable with the other $\mathrm{ShCu}$ cases and is captured by the revised $a_{\mathrm{c}}$-parameterization. As shown in Fig. $3 \mathrm{~b}$, using the proper 


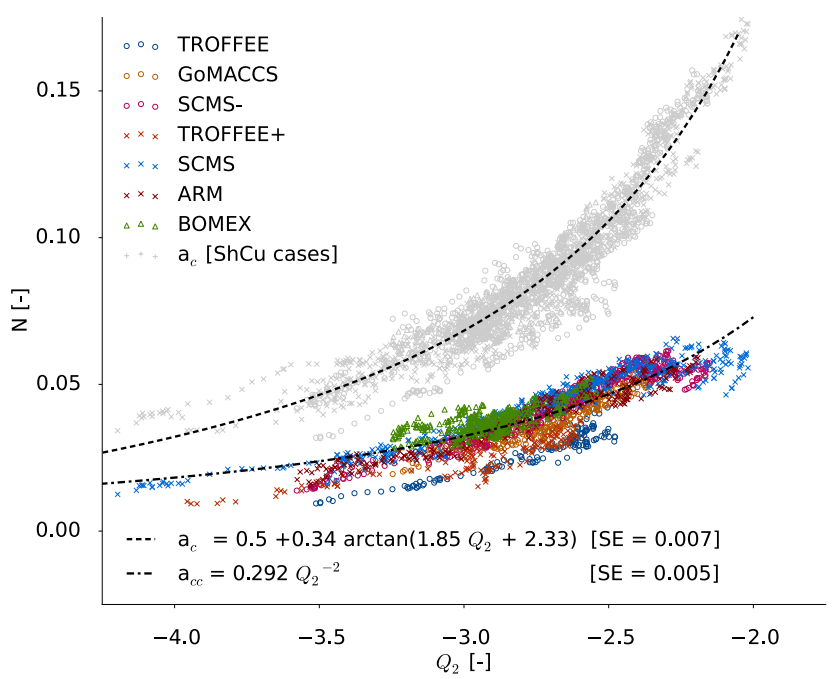

Figure 4. The area fraction of cloud cores $\left(a_{\mathrm{cc}}\right)$ is represented by the coloured symbols, while the $a_{\mathrm{c}}$ for all $\mathrm{ShCu}$ cases is shown in grey. Both area fractions are shown as a function of the normalized saturation deficit at cloud base $\left(Q_{2}\right)$. Crosses denote wind situations, while circles indicate free convection situations. SE represents the residual standard error. The lines represent the best fit parameterizations for $a_{\mathrm{c}}$ and $a_{\mathrm{cc}}$.

index variable, $Q_{2}$, results in a well-defined dependence of cloud area fraction. Furthermore, using this approach we can deduce an accurate parameterization for $a_{\mathrm{c}}$ for all numerical experiments. By using the Levenberg-Marquardt algorithm for least square curve fitting, we find

$a_{\mathrm{c}}=0.5+\alpha \arctan \left(\beta Q_{2}+\gamma\right)$,

where $\alpha=0.34$ (0.002), $\beta=1.85 \quad(0.063)$ and $\gamma=$ 2.33 (0.111). The standard error of the parameter estimate (in parentheses) is calculated with the use of a covariance-matrix over the parameters. The residual standard error yields 0.036 , which is calculated via the reduced chi-squared method. In ATEX and $\mathrm{SCMS}_{\text {cold }}$, both the $\mathrm{ShCu}$ and stratocumulus regimes are generally captured well by Eq. (9), while only the transition between this regime remains troublesome. This deviation is reflected in the relatively large residual standard error. Focusing solely on a cloud fraction lower than $a_{\mathrm{c}}=0.3$, i.e. $\mathrm{ShCu}$ cases, the residual standard error yields 0.007 , as also shown in Fig. 4.

As mentioned before, $a_{\mathrm{cc}}$ cannot be parameterized by the expression for $a_{\mathrm{c}}$. This is confirmed by the $a_{\mathrm{c}}=2.12 a_{\mathrm{cc}}$ relation shown in Fig. 2. In Fig. 4, we show that a separate parameterization is needed for $a_{\mathrm{cc}}$. We derive

$a_{\mathrm{cc}}=0.292 Q_{2}^{-2}$,

where the standard error in the parameter yields 0.001 . The residual error yields 0.005 . In addition to $a_{\mathrm{cc}}$, we display the $a_{\mathrm{c}}$ data (shaded) in Fig. 4, together with its parameterization, to demonstrate that $a_{\mathrm{c}}$ and $a_{\mathrm{cc}}$ can be well-

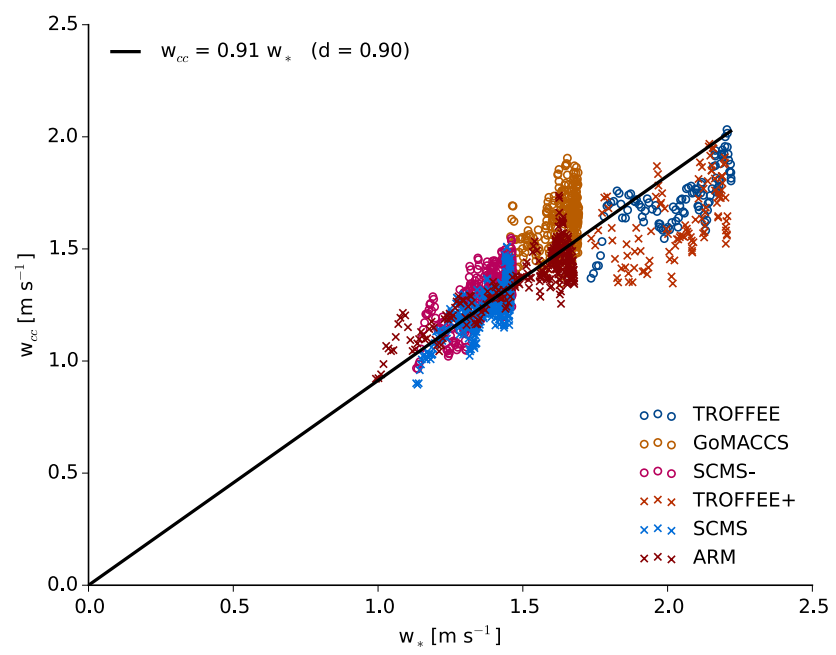

Figure 5. Scaling of the cloud core vertical velocity $\left(w_{\mathrm{cc}}\right)$ as a function of the Deardorff convective velocity scale $\left(w_{*}\right)$. Circles represent free convection situations, crosses indicate wind situations. The line represents a least square fit, which is forced through $0 . d$ represents the index of agreement.

represented independently, but are not similar. As such, using $a_{\mathrm{c}}$ to predict $a_{\mathrm{cc}}$, as is currently assumed in the literature (e.g. Neggers et al., 2006), will lead to poor predictions of the active cloud area fraction. Furthermore, the simplified $a_{\mathrm{c}}$-parameterization of NG06 introduces inconsistencies depending on the evaluated case. Using Eqs. (9) and (10) removes these inconsistencies and is therefore essential to predict in-cloud transport and associated feedbacks accurately. Besides an improved representation of in-cloud transport in mixed-layer models, Eq. (10) is also relevant for global models that deal with the transport of atmospheric compounds other than water (e.g. the EMAC atmospheric chemistryclimate model; Ouwersloot et al., 2015), as the area fraction of active clouds is essential to calculate the correct vertical transport from a grid cell.

\subsection{Scaling of convective transport}

The cloud core vertical velocity, $w_{\mathrm{cc}}$, is the final component of the kinematic mass flux formulation (Eq. 2). In this section, we evaluate the scaling of Neggers et al. (2004) for various atmospheric conditions to complete the kinematic mass flux parameterization. Neggers et al. (2004) showed that the $w_{\text {cc }}$ can be scaled with the Deardorff convective velocity scale $\left(w_{*}\right)$. Building on this work, Ouwersloot et al. (2013) and van Stratum et al. (2014) found that a prefactor of 0.84 improved this scaling. Their analysis was based on four $\mathrm{ShCu}$ cases, where no selection of the data was applied to distinguish between active $\mathrm{ShCu}$ and forced/passive $\mathrm{ShCu}$. Therefore, the presence of forced and passive clouds disturbs the scaling of $w_{\mathrm{cc}}$. As a result, their scaling value is lower due to the weaker vertical velocities related to forced clouds. By 

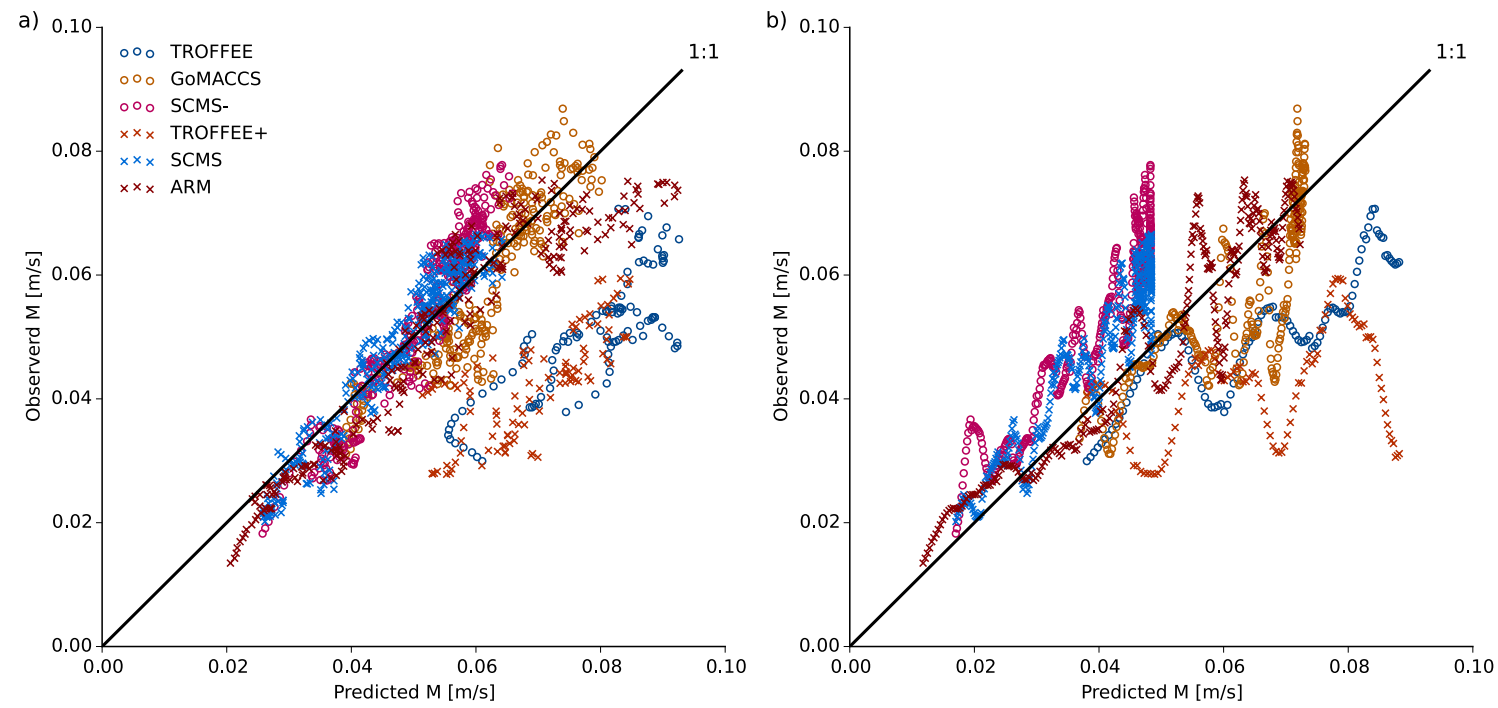

Figure 6. Observed kinematic mass flux $(M)$ as a function of (a) the parameterized kinematic mass flux (using Eqs. 2, 10 and 11$)$ and (b) the scaled surface buoyancy flux divided by the domain-averaged virtual potential temperature at surface, $\alpha \frac{\overline{w^{\prime} \theta_{\mathrm{vs}}^{\prime}}}{\overline{\theta_{\mathrm{vs}}}}$. The scaling factor $\alpha$ is 142 , which is obtained using least square fitting of the $1: 1$ line through the data. Circles represent free convection situations and crosses indicate wind situations.

only taking the active phase into account, we find the following relation (Fig. 5):

$w_{\mathrm{cc}}=0.91 w_{*}$

with $d=0.90$. Compared to the original prefactor, this increases the predicted kinematic mass flux (Eq. 2) by $\sim 8 \%$. The high index of agreement shows that this relation is not affected much by different boundary layer dynamics and structures. However, as is visible in Fig. 5, the TROFFEE case is not as well-represented by the scaling. If we apply a fit through the TROFFEE data, we find a scaling factor of 0.85 $(d=0.74)$, which is comparable to the result of Ouwersloot et al. (2013) who found $0.84(d=0.94)$. The deviation of this case compared to other cases could be explained by a relative deep ABL depth $(\sim 2 \mathrm{~km})$. Combined with a strong surface forcing, $w_{*}$ increases strongly, while the $w_{\mathrm{cc}}$ is not significantly affected. This results in a lower scaling constant.

\subsection{Representation of the kinematic mass flux}

Here, we briefly evaluate the kinematic mass flux prediction by comparing it to the observed kinematic mass flux in the simulations. In Fig. 6a it is shown that the parameterizations result in a good approximation for the observed $M$, even though it is overestimated for the TROFFEE case. We hypothesize that this latter exception is related to the deep $(\sim 2 \mathrm{~km})$ boundary layer, which only enables cloud growth for the most vigorous upward directed thermals with a high moisture level. When these thermals reach the LCL, the difference in moisture with its surrounding air is relatively high, leading to high values of $\sigma_{q}$ and consequently a higher pre- dicted $a_{\mathrm{cc}}$ than physically present. This hypothesis is supported by the small time span these active clouds are present during the most convective time of the day (Fig. 1). To compare our prediction of the kinematic mass flux, based on separately parameterizing the cloud core area fraction and in-cloud vertical velocity, with the result one would obtain by making direct use of a proxy, we show the relation between the observed $M$ and the scaled surface buoyancy flux in Fig. 6b. In this figure, the predicted $M$ is equal to $\alpha \frac{\overline{w^{\prime} \theta_{\mathrm{vs}}^{\prime}}}{\overline{\theta_{\mathrm{vs}}}}$, where $\overline{w^{\prime} \theta_{\mathrm{vs}}^{\prime}}$ and $\overline{\theta_{\mathrm{vs}}}$ denote the surface buoyancy flux and domain-averaged surface virtual potential temperature, respectively, and $\alpha=142$, based on linear regression. This prediction method could alternatively be used to roughly estimate the kinematic mass flux, however it is less accurate than the prediction obtained by combining the two separate parameterizations for $a_{\mathrm{cc}}$ and $w_{\mathrm{cc}}$. Again, the TROFFEE case is less well represented, which is most likely due to the specific atmospheric profile as mentioned before. In conclusion, the prediction of the kinematic mass flux is improved by making use of the parameterizations for its two main components $\left(a_{\mathrm{cc}}\right.$ and $\left.w_{\mathrm{cc}}\right)$ compared to scaling with the surface buoyancy flux. Furthermore, as a result, we have information on both the in-cloud vertical velocity and the area fraction of active clouds, which is valuable information for atmospheric models that need parameterizations to represent convective transport of atmospheric compounds. 


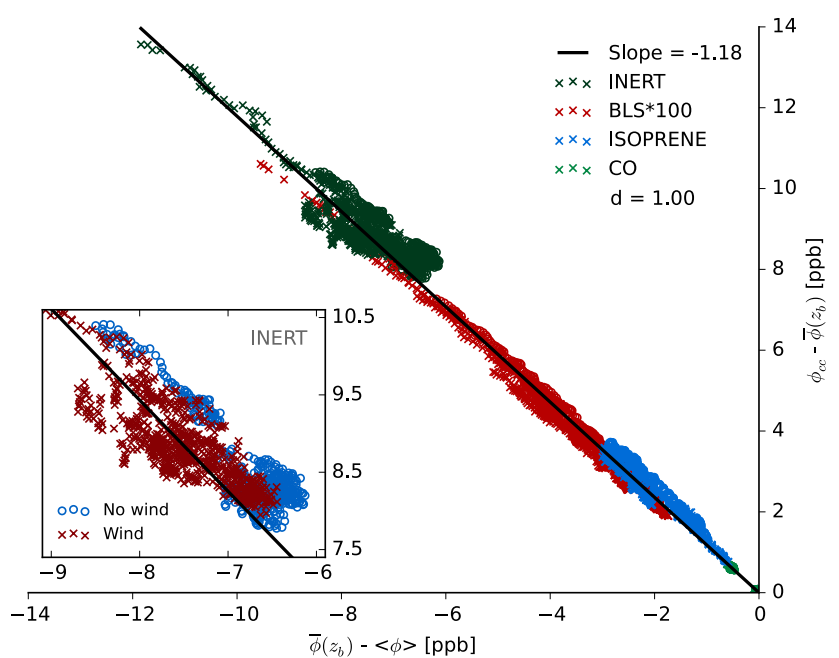

Figure 7. Parameterization for $\phi_{\mathrm{cc}}-\bar{\phi}\left(z_{\mathrm{b}}\right)$ as a function of $\bar{\phi}\left(z_{\mathrm{b}}\right)-$ $\langle\phi\rangle$ proposed by Ouwersloot et al. (2013). Here, $\phi$ represents the 24 transported species (note that only INERT, BLS, isoprene and $\mathrm{CO}$ are shown). Circles represent free convection situations, crosses indicate wind situations. The solid line represents a least square fit through all data, which is forced through $0 . d$ represents the index of agreement. The inset shows solely the INERT species for wind and no wind experiments.

\subsection{Parameterizing reactant transport}

In this section we focus on the final component of the expression for convective transport of atmospheric compounds (Eq. 1), namely the concentration of chemical species at cloud base, $\left(\phi_{\mathrm{cc}}-\bar{\phi}\left(z_{\mathrm{b}}\right)\right)$. The parameterization, proposed by Ouwersloot et al. (2013), showed that the concentrations of chemical species at the base of active $\mathrm{ShCu}$ can be predicted by Eq. (8) for a tropical case (TROFFEE). However, they stress that ABL dynamics could influence the parameterization. Therefore, we test the parameterization for all continental $\mathrm{ShCu}$ cases. The relation is illustrated for four chemical species (i.e., INERT, BLS, isoprene and CO) in Fig. 7, but the least squares regression is fit through all 24 evaluated chemical species. This yields:

$\phi_{\mathrm{cc}}-\bar{\phi}\left(z_{\mathrm{b}}\right) \approx-1.18\left(\bar{\phi}\left(z_{\mathrm{b}}\right)-\langle\phi\rangle\right)$.

For all relations, the index of agreement is 1.00 .

We find similar results as Ouwersloot et al. (2013) but our constant is slightly less negative than their -1.23 . Since we use the least squares method to find the optimum scaling constant, it means that compounds with the largest differences between $\left(\phi\left(z_{\mathrm{b}}\right)-\langle\phi\rangle\right)$ affect the scaling constant the most. As shown in Fig. 7, this means that INERT has a dominating influence. Focusing on this compound (inset), we find that wind tends to increase the differences between species in the cloud core compared to their average at cloud base, while for a free convection situation the opposite is visible. As a result, the closure constant of Eq. (12) shifts slightly. This results in

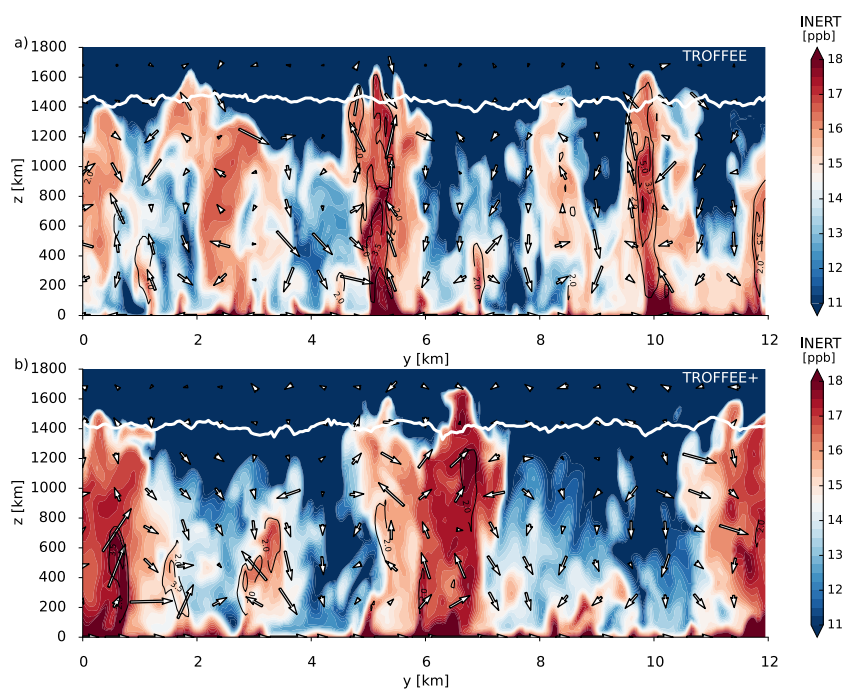

Figure 8. Vertical cross sections of INERT for the TROFFEE case for (a) a free convection situation and (b) a wind situation. The white arrows indicate wind vectors of the $v$ and $w$ component. In panel (b), the mean horizontal wind is subtracted from the flow to identify the vertical patterns. The white horizontal line around $1400 \mathrm{~m}$ denotes the ABL height, which is calculated using the threshold gradient method. In black, contour lines are shown for $w$, starting at a lower limit of $2 \mathrm{~m} \mathrm{~s}^{-1}$ with intervals of $1.5 \mathrm{~m} \mathrm{~s}^{-1}$.

a slope of -1.17 in case of wind and a slope of -1.19 in case of free convection (not shown). We identify that dynamical segregation is occurring in the ABL, as shown for INERT in Fig. 8 and discussed by Ouwersloot et al. (2013) for a tropical case. Rising motions in the ABL transport high concentrations of the emitted species upwards, while lower concentrations of INERT are found in the downward motions. Therefore, higher concentrations of species are transported towards the free troposphere by cloud venting as would be expected compared to a well-mixed situation. Although the effects of chemical segregation are usually small for clear sky situations, they can be substantial for cloud-topped boundary layers due to cloud venting. As a result, the chemical parameterizations and scalings are affected. Furthermore, as is shown in Fig. 8, wind affects the distance and upward velocities in the thermals, resulting in less, but wider thermals in our domain. This affects the vertical transport of species and decreases this transport (max. $3.5 \mathrm{~m} \mathrm{~s}^{-1}$ ) compared to a free convection situation $\left(\max .5 .0 \mathrm{~m} \mathrm{~s}^{-1}\right.$ ) where the thermals are narrower. As a result, the transport of chemical species to the cloud layer is less in the wind case, resulting in a smaller difference between $\phi_{\mathrm{cc}}$ and $\bar{\phi}\left(z_{\mathrm{b}}\right)$, which decreases the magnitude of the scaling constant of Eq. (12). Next to an effect on convective transport, one has to note that dynamical segregation also modifies the mean reactivity in the ABL, as was shown by Ouwersloot et al. (2011) for clear sky conditions and $\mathrm{Kim}$ et al. (2004) in $\mathrm{ShCu}$ situations. 


\section{Conclusions}

The representation of sub-grid convective transport of atmospheric compounds by boundary layer clouds is investigated. We focus on three key parameterizations that express this transport, namely, the area fraction of clouds, the upward velocity in the cloud cores and the concentrations at cloud base. The parameterizations are investigated under a wide range of conditions with the use of large-eddy simulation (LES) model data from seven boundary layer cloud cases, ranging from shallow cumulus (partly cloud cover) to stratocumulus (totally overcast). Next to the seven standard boundary layer cloud cases, three additional cases are simulated that are slightly adapted to provide additional information needed for deriving the parameterizations.

We found that the simplified statistical cloud area fraction parameterization, and the combined variables it uses as input, are influenced by the structure of the atmospheric boundary layer (ABL). Therefore, the parameterization was not applicable to a wide range of conditions. We simplified and updated this parameterization by considering the variability in moisture rather than the saturation deficit, and show that this parameterization has to be evaluated locally to capture cloud presence accurately. Furthermore, we demonstrate that the parameterization for the total cloud area fraction cannot be used to represent the area fraction of active clouds, as is currently assumed in the literature. This leads to an overestimation of the in-cloud mass transport when this parameterization is used. To capture this cloud transport properly, we propose a novel parameterization. Besides its usefulness in mixed-layer models, the parameterizations are also relevant for global models to capture the area fraction of a grid cell in which chemicals are drained to upper layers.

Moreover, we evaluated the scaling of the cloud core vertical velocity with the Deardorff convective velocity scale by using six continental representative $\mathrm{ShCu}$ cases. We found that the previously published relation holds, but that a higher closure constant is needed, which corresponds to an increase of the convective mass transport by $\sim 8 \%$. Combining the parameterizations for the area fraction of active clouds and the cloud core vertical velocity, we predict the kinematic mass flux. The comparison between this prediction and observed LES values demonstrated that we are able to accurately represent the kinematic mass flux induced by $\mathrm{ShCu}$ clouds, applicable over a wide range of conditions.

Lastly, the parameterization of reactant concentrations at the base of active clouds was investigated for six continental $\mathrm{ShCu}$ cases, as in previous literature it was only validated for a tropical case. We found a minor spread in the derived closure constants for the parameterization, depending on whether a background wind was present or not, which can be explained by the affected dynamical segregation of chemical species in the ABL. However, this spread was small and a general derived closure constant can be applied for parameterizations in large-scale models. In total, we validated and updated three robust parameterizations and proposed a novel parameterization essential for $\mathrm{ShCu}$ venting. These provide information on both the vertical velocity in and the area fraction of active clouds. This is valuable for atmospheric models that need parameterizations to represent convective transport of atmospheric compounds, occurring at a sub-grid scale.

Acknowledgements. The authors would like to thank Jordi VilàGuerau de Arellano for the insightful discussions and comments. We also thank W. Angevine and an anonymous reviewer who helped improve the quality of this work. The numerical simulations were performed with the supercomputer facilities at SURFsara and sponsored by the project NCF-NWO SH-060-13.

The article processing charges for this open-access publication were covered by the Max Planck Society.

Edited by: P. Chuang

\section{References}

Arakawa, A.: The Cumulus Parameterization Problem: past, present and future, J. Climate, 17, 2493-2525, doi:10.1175/15200442(2004)017<2493:RATCPP>2.0.CO;2, 2004.

Bechtold, P., Bazile, E., Guichard, F., Mascart, P., and Richard, E.: A mass-flux convection scheme for regional and global models, Q. J. Roy. Meteor. Soc., 127, 869-886, doi:10.1002/qj.49712757309, 2001.

Betts, A. K.: Non-precipitating cumulus convection and its parameterization, Q. J. Roy. Meteor. Soc., 99, 178-196, doi:10.1002/qj.49709941915, 1973.

Betts, A. K.: A new convective adjustment scheme, Part I: Observational and theoretical basis, Q. J. Roy. Meteor. Soc., 112, 677691, doi:10.1002/qj.49711247307, 1986.

Boing, S. J., Jonker, H. J. J., Nawara, W., and Siebesma, A. P.: On the deceiving aspects of mixing diagrams of deep cumulus convection, J. Atmos. Sci., 71, 56-68, doi:10.1175/JAS-D-130127.1, 2014.

Boucher, O., Randall, D., Artaxo, P., Bretherton, C., Feingold, G., Forster, P., Kerminen, V.-M., Kondo, Y., Liao, H., Lohmann, U., Rasch, P., Satheesh, S. K., Sherwood, S., Stevens, B., and Zhang, X. Y.: Clouds and aerosols, in: Climate Change 2013: The Physical Science Basis, Contribution of Working Group I to the Fifth Assessment Report of the Intergovernmental Panel on Climate Change, Cambridge University Press, Cambridge, UK, New York, NY, USA, 571-657, 2013.

Bretherton, C. S., McCaa, J. R., and Grenier, H.: A new parameterization for shallow cumulus convection and its application to marine subtropical cloud-topped boundary layers, Part I: Description and 1D results, Mon. Weather Rev., 132, 864-882, doi:10.1175/1520-0493(2004)132<0864:ANPFSC >2.0.CO;2, 2003.

Brown, A. R., Cederwall, R. T., Chlond, A., Duynkerke, P. G., Golaz, J. C., Khairoutdinov, M., Lewellen, D. C., Lock, A. P., Macvean, M. K., Moeng, C. H., Neggers, R. A. J., Siebesma, A. P., and Stevens, B.: Large-eddy simulation of the diurnal cycle of shallow cumulus convec- 
tion over land, Q. J. Roy. Meteor. Soc., 128, 1075-1093, doi:10.1256/003590002320373210, 2002.

Cuijpers, J. W. M. and Bechtold, P.: A simple parameterization of cloud water related variables for use in boundary layer models, J. Atmos. Sci., 52, 2486-2490, doi:10.1175/15200469(1995)052<2486:ASPOCW>2.0.CO;2, 1995.

Deardorff, J. W.: Convective velocity and temperature scales for the unstable planetary boundary layer and for Rayleigh convection, J. Am. Meteorol. Soc., 27, 1211-1213, doi:10.1175/15200469(1970)027<1211:CVATSF>2.0.CO;2, 1970.

de Rooy, W. C. and Siebesma, A. P.: A simple parameterization for detrainment in shallow cumulus, Mon. Weather Rev., 136, 560576, doi:10.1175/2007MWR2201.1, 2008.

Heus, T., van Heerwaarden, C. C., Jonker, H. J. J., Pier Siebesma, A., Axelsen, S., van den Dries, K., Geoffroy, O., Moene, A. F., Pino, D., de Roode, S. R., and Vilà-Guerau de Arellano, J.: Formulation of the Dutch Atmospheric Large-Eddy Simulation (DALES) and overview of its applications, Geosci. Model Dev., 3, 415-444, doi:10.5194/gmd-3-415-2010, 2010.

Holland, J. Z. and Rasmusson, E. M.: Measurements of the atmospheric mass, energy, and momentum budgets over a 500-Kilometer square of tropical ocean, Mon. Weather Rev., 101, 45-57, doi:10.1175/15200493(1973)101<0044:MOTAME>2.3.CO;2, 1973.

Horn, G. L., Ouwersloot, H. G., Vilà-Guerau de Arellano, J., and Sikma, M.: Cloud shading effects on characteristic boundary layer length scales, Bound.-Lay. Meteor., doi:10.1007/s10546015-0054-4, online first, 2015.

Jiang, H., Feingold, G., Jonsson, H. H., Lu, M.-L., Chuang, P. Y., Flagan, R. C., and Seinfeld, J. H.: Statistical comparison of properties of simulated and observed cumulus clouds in the vicinity of Houston during the Gulf of Mexico Atmospheric Composition and Climate Study (GoMACCS), J. Geophys. Res., 113, D13205, doi:10.1029/2007JD009304, 2008.

Karl, T., Guenther, A., Yokelson, R. J., Greenberg, J., Potosnak, M., Blake, D. R., and Artaxo, P.: The tropical forest and fire emissions experiment: Emission, chemistry, and transport of biogenic volatile organic compounds in the lower atmosphere over Amazonia, J. Geophys. Res., 112, D18302, doi:10.1029/2007JD008539, 2007.

Kim, S.-W., Barth, M. C., and Moeng, C.-H.: The effect of shallow cumulus convection on the segregation of chemical reactants, 16th Symposium on Boundary Layers and Turbulence, 9-13 August 2014, Portland, USA, 67-70, 2004.

Lenderink, G. and Siebesma, A. P.: Combining the mass flux approach with a statistical cloud scheme, in: Proceedings of the 14th Symposium on Boundary Layer and Turbulence, 7-11 August 2000, Aspen, USA, 66-69, 2000.

Lohou, F. and Patton, E.: Surface energy balance and buoyancy response to shallow cumulus shading, J. Atmos. Sci., 71, 665-682, doi:10.1175/JAS-D-13-0145.1, 2014.

Neggers, R. A. J., Duynkerke, P. G., and Rodts, S. M. A.: Shallow cumulus convection: a validation of large-eddy simulation against aircraft and Landsat observations, Q. J. Roy. Meteor. Soc., 129, 2671-2696, doi:10.1256/qj.02.93, 2003.

Neggers, R. A. J., Siebesma, A., Lenderink, G., and Holtslag, A.: An evaluation of mass flux closures for diurnal ccycle of shallow cumulus, Mon. Weather Rev., 132, 2525-2538, doi:10.1175/MWR2776.1, 2004.
Neggers, R. A. J., Stevens, B., and Neelin, J. D.: A simple equilibrium model for shallow-cumulus-topped mixed layers, Theor. Comput. Fluid Dyn., 20, 305-322, doi:10.1007/s00162-0060030-1, 2006.

Ouwersloot, H. G., Vilà-Guerau de Arellano, J., van Heerwaarden, C. C., Ganzeveld, L. N., Krol, M. C., and Lelieveld, J.: On the segregation of chemical species in a clear boundary layer over heterogeneous land surfaces, Atmos. Chem. Phys., 11, 1068110704, doi:10.5194/acp-11-10681-2011, 2011.

Ouwersloot, H. G., Vilà-Guerau de Arellano, J., van Stratum, B. J. H., Krol, M. C., and Lelieveld, J.: Quantifying the transport of subcloud layer reactants by shallow cumulus clouds over the Amazon, J. Geophys. Res., 118, 13041-13059, doi:10.1002/2013JD020431, 2013.

Ouwersloot, H. G., Pozzer, A., Steil, B., Tost, H., and Lelieveld, J.: Revision of the convective transport module CVTRANS 2.4 in the EMAC atmospheric chemistry-climate model, Geosci. Model Dev., 8, 2435-2445, doi:10.5194/gmd-8-2435-2015, 2015.

Siebesma, A. P., Bretherton, C. S., Brown, A., Chlond, A., Cuxart, J., Duynkerke, P. G., Jiang, H., Khairoutdinov, M., Lewellen, D., Moeng, C., Sanchez, E., Stevens, B., and Stevens, D. E.: A large eddy simulation intercomparison study of shallow cumulus convection, J. Atmos. Sci., 60, 1201-1219, doi:10.1175/1520-0469(2003)60<1201:ALESIS>2.0.CO;2, 2003.

Sikma, M., Vilà-Guerau de Arellano, J., and Ouwersloot, H. G.: An elementary shallow cumulus parameterization for tropical boundary layers, in: Proceedings of the 5th Student Research Conference, 26 November 2014, Delft, the Netherlands, 103106, 2014.

Soares, P. M. M., Miranda, P. M. A., Siebesma, A. P., and Teixeira, J.: An eddy-diffusivity/mass-flux parametrization for dry and shallow cumulus convection, Q. J. Roy. Meteor. Soc., 130, 3365-3383, doi:10.1256/qj.03.223, 2004.

Sorooshian, A., Lu, M.-L., Brechtel, F. J., Jonsson, H., Feingold, G., Flagan, R. C., and Seinfeld, J. H.: On the source of organic acid aerosol layers above clouds, Environ. Sci. Technol., 41, 46474654, doi:10.1021/es0630442, 2007.

Stevens, B., Ackerman, A. S., Albrecht, B. A., Brown, A. R., Chlond, A., Cuxart, J., Duynkerke, P. G., Lewellen, D. C., Macvean, M. K., Neggers, R. A. J., Sanchez, E., Siebesma, A. P., and Stevens, D. E.: Simulations of trade wind cumuli under a strong inversion, J. Atmos. Sci., 58, 1870-1891, doi:10.1175/1520-0469(2001)058<1870:SOTWCU>2.0.CO;2, 2001.

Stevens, B., Moeng, C.-H., Ackerman, A. S., Bretherton, C. S., Chlond, A., de Roode, S., Edwards, J., Golaz, J. C., Jiang, H., Khairoutdinov, M., Kirkpatrick, M. P., Lewellen, D. C., Lock, A., Muller, F., Stevens, D. E., Whelan, E., and Zhu, P.: Evaluation of large-eddy simulations via observations of nocturnal marine stratocumulus, Mon. Weather Rev., 133, 1443-1462, doi:10.1175/MWR2930.1, 2005.

Stull, R. B.: A fair weather cumulus cloud classification scheme for mixed layer studies, J. Clim. Appl. Meteorol., 24, 49-56, doi:10.1175/1520-0450(1985)024<0049:AFWCCC>2.0.CO;2, 1985.

Suselj, K., Teixeira, J., and Chung, D.: A unified model for moist convective boundary layers based on a stochastic eddy- 
diffusivity/mass-flux parameterization, J. Atmos. Sci., 70, 19291953, doi:10.1175/JAS-D-12-0106.1, 2013.

van Stratum, B. J. H., Vilà-Guerau de Arellano, J., van Heerwaarden, C. C., and Ouwersloot, H. G.: Subcloud-layer feedback driven by the mass flux of shallow cumulus convection over land, J. Atmos. Sci., 71, 881-895, doi:10.1175/JAS-D-130192.1, 2014.

Vilà-Guerau de Arellano, J., Kim, S.-W., Barth, M. C., and Patton, E. G.: Transport and chemical transformations influenced by shallow cumulus over land, Atmos. Chem. Phys., 5, 3219-3231, doi:10.5194/acp-5-3219-2005, 2005.
Vilà-Guerau de Arellano, J., van Heerwaarden, C. C., and Lelieveld, J.: Modelled suppression of boundary-layer clouds by plants in a $\mathrm{CO}_{2}$-rich atmosphere, Nat. Geosci., 5, 701-704, doi:10.1038/NGEO1554, 2012.

Vilà-Guerau de Arellano, J., Ouwersloot, H. G., Baldocchi, D., and Jacobs, C.: Shallow cumulus rooted in photosynthesis, Geophys. Res. Lett., 41, 1796-1802, doi:10.1002/2014GL059279, 2014.

Wilmott, C. J.: On the validation of models, Phys. Geogr., 2, 184 194, 1981. 